\title{
Light-induced phase transition and photochromism in all-inorganic two-dimensional $\mathrm{Cs}_{2} \mathrm{Pbl}_{2} \mathrm{Cl}_{2}$ perovskite
}

\author{
Xiaojun $\mathrm{Li}^{1}$, Mingming $\mathrm{Chen}^{2}$, Shiliang $\mathrm{Mei}^{1}$, Bingzhe Wang ${ }^{1}$, Kaiyang Wang ${ }^{1}$, Guichuan Xing ${ }^{{ }^{*}}$ and \\ Zikang Tang ${ }^{1 *}$
}

\begin{abstract}
Organic-inorganic hybrid two-dimensional (2D) ruddlesden-popper (RP) perovskites with fantastic optoelectronic properties and good stability have attracted tremendous attention for the potential applications in photovoltaics and electroluminescence. Recently, a new allinorganic $\mathrm{Cs}_{2} \mathrm{PbI}_{2} \mathrm{Cl}_{2} 2 \mathrm{D}$ perovskite has been proposed with excellent excitonic absorption and improved ambient and thermal stability. Herein, an interesting light-induced phase transition and photochromism in the $\mathrm{Cs}_{2} \mathrm{PbI}_{2} \mathrm{Cl}_{2}$ were reported. Under low fluence light pumping, the room temperature photoluminescence $(\mathrm{PL})$ of $\mathrm{Cs}_{2} \mathrm{PbI}_{2} \mathrm{Cl}_{2}$ is dominated by a weak violet excitonic emission peaked at $412 \mathrm{~nm}$. Surprisingly, the emission color gradually changes from violet to bright red while increasing the laser pumping fluence. This photochromic effect is determined to be caused by forming $\mathrm{CsPbI}_{3}$ phase within the $\mathrm{Cs}_{2} \mathrm{PbI}_{2} \mathrm{Cl}_{2}$ crystals, which is efficiently driven by thermal energy. Due to protection by the $\mathrm{Cs}_{2} \mathrm{PbI}_{2} \mathrm{Cl}_{2}$ matrix, the embedded $\mathrm{CsPbI}_{3}$ nanocrystals show improved stability than standard pure $\mathrm{CsPbI}_{3}$. Therefore, the $\mathrm{Cs}_{2} \mathrm{PbI}_{2} \mathrm{Cl}_{2}$ perovskite with photochromic feature may find applications in optical encryption, as preliminarily shown in this work.
\end{abstract}

Keywords: $\mathrm{Cs}_{2} \mathrm{PbI}_{2} \mathrm{Cl}_{2}$, light-induced phase transition, photochromism, optical encryption

\section{INTRODUCTION}

Metal-halide perovskites have demonstrated tremendous potentials in photovoltaics, light-emitting diodes, lasers and photodetectors for their excellent optoelectronic properties [1-9]. Among the lead-perovskites family, in recent years, cesium lead halide perovskites, due to their outstanding optoelectronic properties and improved sta- bility, have attracted much more attention [10-14]. Based on the connection manner of the $\mathrm{PbX}_{6}$ octahedra, in the aspect of dimensionality, cesium lead halide perovskites can be classified into three-dimensional (3D) $\mathrm{CsPbX}_{3}$ (corner-shared octahedra, $\mathrm{X}$ is halogen), $2 \mathrm{D} \mathrm{Cs}_{2} \mathrm{PbX}_{4}$ or $\mathrm{CsPb}_{2} \mathrm{X}_{5}$ (octahedra planes), $1 \mathrm{D} \quad \mathrm{Cs}_{3} \mathrm{PbX}_{5}$ (octahedra chains) and $0 \mathrm{D} \mathrm{Cs}_{4} \mathrm{PbX}_{6}$ crystal structures. Among them, $2 \mathrm{D}$ ruddlesden-popper (RP) phase $\mathrm{Cs}_{2} \mathrm{PbX}_{4}$ owns an important and special position and gains more and more attention, due to its stable optoelectronic properties and substantially improved stability. Very recently, Li and coworkers [15] reported 2D RP phase $\mathrm{Cs}_{2} \mathrm{PbI}_{2} \mathrm{Cl}_{2}$ bulk materials synthesized by a solid-state method and characterized their excellent in-plane UV-light photoresponse and markedly ambient and thermal stability. In addition, theoretical studies predicted a rather high, layer-dependent in-plane electron mobilities as high as $\sim 9.39 \times 10^{3} \mathrm{~cm}^{2} \mathrm{~V}^{-1} \mathrm{~s}^{-1}$ in the $2 \mathrm{D}$ bilayer $\mathrm{Cs}_{2} \mathrm{PbI}_{2} \mathrm{Cl}_{2}$ [16]. Then shortly after that, a strong excitonic absorption but with a weak photoluminescence (PL) quantum yield has been found in the photophysical research of $\mathrm{Cs}_{2} \mathrm{PbI}_{2} \mathrm{Cl}_{2}$ nanoparticles $[17,18]$. Further studies showed that the strong PL quenching may be caused by the combination of iodide segregation and defective RP phase interfaces. However, noticeably, doping and post-synthetic chemical transformation of $\mathrm{Cs}_{2} \mathrm{PbI}_{2} \mathrm{Cl}_{2}$ may provide application opportunities in the optoelectronic field $[18,19]$.

In general, phase transition (or degeneration) occurs when the temperature reaches up to a specific value. This thermo-induced phase transition originates from the transformation or reconstruction of crystal structure. Theoretically, phase transition may occur even at room temperature if the raw material receives enough energy

\footnotetext{
${ }^{1}$ Institute of Applied Physics and Materials Engineering, University of Macau, Avenida da Universidade, Taipa, Macau 999078, China

${ }^{2}$ Department of Physics, Jiangsu University, Zhenjiang 212013, China

* Corresponding authors (emails: gcxing@um.edu.mo (Xing G); zktang@um.edu.mo (Tang Z))
} 
from incident light via the photothermal process [20]. Such a transition can be termed as a light-induced structural phase transition. For a semiconductor, lightinduced structural phase transition often leads to modulation of morphological, electrical and optical properties [21-23]. Accordingly, such materials with light-induced phase transition may have great applications in signal transformation and optical encryption fields.

Herein, the light-induced phase transition features of all-inorganic perovskite $2 \mathrm{D} \mathrm{RP}$ phase $\mathrm{Cs}_{2} \mathrm{PbI}_{2} \mathrm{Cl}_{2}$ have been demonstrated for the first time. It shows that the room temperature PL spectra are dominated by weak violet (strong red) emission before (after) phase transition. According to X-ray diffraction (XRD) and transmission electron microscopy (TEM) measurements, the unexpected red emission band comes from reconstruction of $\mathrm{CsPbI}_{3}$ nanocrystals inside the $\mathrm{Cs}_{2} \mathrm{PbI}_{2} \mathrm{Cl}_{2}$. Due to the protection of $\mathrm{Cs}_{2} \mathrm{PbI}_{2} \mathrm{Cl}_{2}$ matrix microcrystals, the $\mathrm{CsPbI}$-in- $\mathrm{Cs}_{2} \mathrm{PbI}_{2} \mathrm{Cl}_{2}$ composite shows an improved stability than pure $\mathrm{CsPbI}_{3}$. Finally, optical encryption based on $\mathrm{Cs}_{2} \mathrm{PbI}_{2} \mathrm{Cl}_{2}$ is preliminarily performed.

\section{EXPERIMENTAL SECTION}

\section{Preparation of large sized $\mathrm{Cs}_{2} \mathrm{PbI}_{2} \mathrm{Cl}_{2}$ microplates}

The square $\mathrm{Cs}_{2} \mathrm{PbI}_{2} \mathrm{Cl}_{2}$ microplates were synthesized by the antisolvent vapor-assisted slow crystallization method [24]. All the raw materials were purchased from SigmaAldrich (USA). According to stoichiometric ratio of $\mathrm{Cs}_{2} \mathrm{PbI}_{2} \mathrm{Cl}_{2}, 0.1 \mathrm{mmol} \mathrm{CsI} \mathrm{(grade} 99.99 \%$ ) and $0.05 \mathrm{mmol}$ $\mathrm{PbCl}_{2}$ (grade 99.99\%) (2CsI+ $\mathrm{PbCl}_{2}$ ) were dissolved in $3 \mathrm{~mL} \mathrm{~N}, \mathrm{~N}$-dimethylformamide (DMF, anhydrous, grade 99.99\%) solvent, which is defined as precursor solution I. $0.1 \mathrm{mmol} \mathrm{CsCl}$ (grade 99.99\%) and $0.05 \mathrm{mmol} \mathrm{PbI}_{2}$ (grade 99.99\%) (2CsCl+ $\left.\mathrm{PbI}_{2}\right)$ were dissolved in $1.5 \mathrm{~mL}$ DMF and $1.5 \mathrm{~mL}$ dimethyl sulfoxide (DMSO, anhydrous, grade $99.99 \%$ ), which is defined as precursor solution II. A glass platform was immersed in the precursor solution I or II in a small bottle, which was placed in $3 \mathrm{~mL}$ antisolvent dichloromethane (DCM, anhydrous, grade 99.99\%) contained in a beaker, and then the beaker was sealed. After $24 \mathrm{~h}$ at room temperature, all DCM had slowly diffused into the precursor solution, which drove the slow crystallization of $\mathrm{Cs}_{2} \mathrm{PbI}_{2} \mathrm{Cl}_{2}$. Then, the glass platform was taken out and placed on the heating stage at $100^{\circ} \mathrm{C}$ for $5 \mathrm{~s}$. The above method was used to prepare dense square $\mathrm{Cs}_{2} \mathrm{PbI}_{2} \mathrm{Cl}_{2}$ microplates with sizes of $10-20 \mu \mathrm{m}$. In addition, another method as follow was used to prepare sparse square $\mathrm{Cs}_{2} \mathrm{PbI}_{2} \mathrm{Cl}_{2}$ microplates. The glass platform was dripped with $200 \mu \mathrm{L}$ solution I or II and suspended above the $3 \mathrm{~mL}$ antisolvent DCM. After the growth was kept at room temperature for $24 \mathrm{~h}$, the glass platform was taken out and placed on the heating stage at $100^{\circ} \mathrm{C}$ for $5 \mathrm{~s}$.

\section{Preparation of small sized $\mathrm{Cs}_{2} \mathrm{PbI}_{2} \mathrm{Cl}_{2}$ microcrystalline thin film}

The $\mathrm{Cs}_{2} \mathrm{PbI}_{2} \mathrm{Cl}_{2}$ microcrystalline thin film was synthesized by the antisolvent dripping-assisted fast crystallization method [24]. $3 \mathrm{~mL}$ antisolvent DCM was dripped into precursor solution I or II in a bottle holding a glass platform. The obtained suspension was stirred for $10 \mathrm{~s}$ at $500 \mathrm{r} \mathrm{s}^{-1}$, then stranded at room temperature. After $6 \mathrm{~h}$, the glass platform was taken out and placed on the heating stage at $100^{\circ} \mathrm{C}$ for $5 \mathrm{~s}$.

\section{Characterizations}

The morphologies and sizes of the obtained $\mathrm{Cs}_{2} \mathrm{PbI}_{2} \mathrm{Cl}_{2}$ were characterized by scanning electron microscopy (SEM, Zeiss Zigma field emission scanning electron microscope, Germany). The elemental composition and distribution were measured by energy-dispersive X-ray spectroscopy (EDX, TEAM Apollo XL, USA). PL spectra of the samples were monitored by a micro Raman system (Horiba LABHRev-UV, USA) under $325 \mathrm{~nm}$ continuous wavelength $(\mathrm{CW})$ laser excitation. Light-induced phase transition was realized by $325 \mathrm{~nm} \mathrm{CW}$ laser excitation source. PL spectra of the heated $\mathrm{Cs}_{2} \mathrm{PbI}_{2} \mathrm{Cl}_{2}$ at $550 \mathrm{~K}$ were collected by a PL3-211-P spectrometer (Horiba Jobin Yvon, USA) and a $450 \mathrm{~W}$ xenon lamp was used as the excitation source. Thermo-induced phase transition was realized by a homothermal heating stage. Absorption spectrum was measured by an ultraviolet visible nearinfrared spectrophotometer (UV3600) using $\mathrm{BaSO}_{4}$ as a reference in the range of $200-800 \mathrm{~nm}$. Phase compositions were tested by powder XRD (Rigaku Smartlab diffractometer, Japan) with $\mathrm{Cu} \mathrm{Ka}$ radiation $(\lambda=1.5405 \AA)$ over the angular range of $10^{\circ} \leq 2 \theta \leq 80^{\circ}$, operated at $45 \mathrm{kV}$ and $200 \mathrm{~mA}$. The scanning TEM image was obtained using an FEI Talos F200X (USA) at an accelerating voltage of $200 \mathrm{kV}$. The pulse laser-excited PL spectra were tested by a femtosecond amplified laser system (pulse width: $100 \mathrm{fs}$; repetition rate: $1000 \mathrm{~Hz}$ ) with $400 \mathrm{~nm}$ excitation and emission light being coupled and collected through the SP-2300 spectrometer and CCD detector. All the above measurements were performed at room temperature.

\section{RESULTS AND DISCUSSION}

Herein, two types of $\mathrm{Cs}_{2} \mathrm{PbI}_{2} \mathrm{Cl}_{2}$ microplates were syn- 

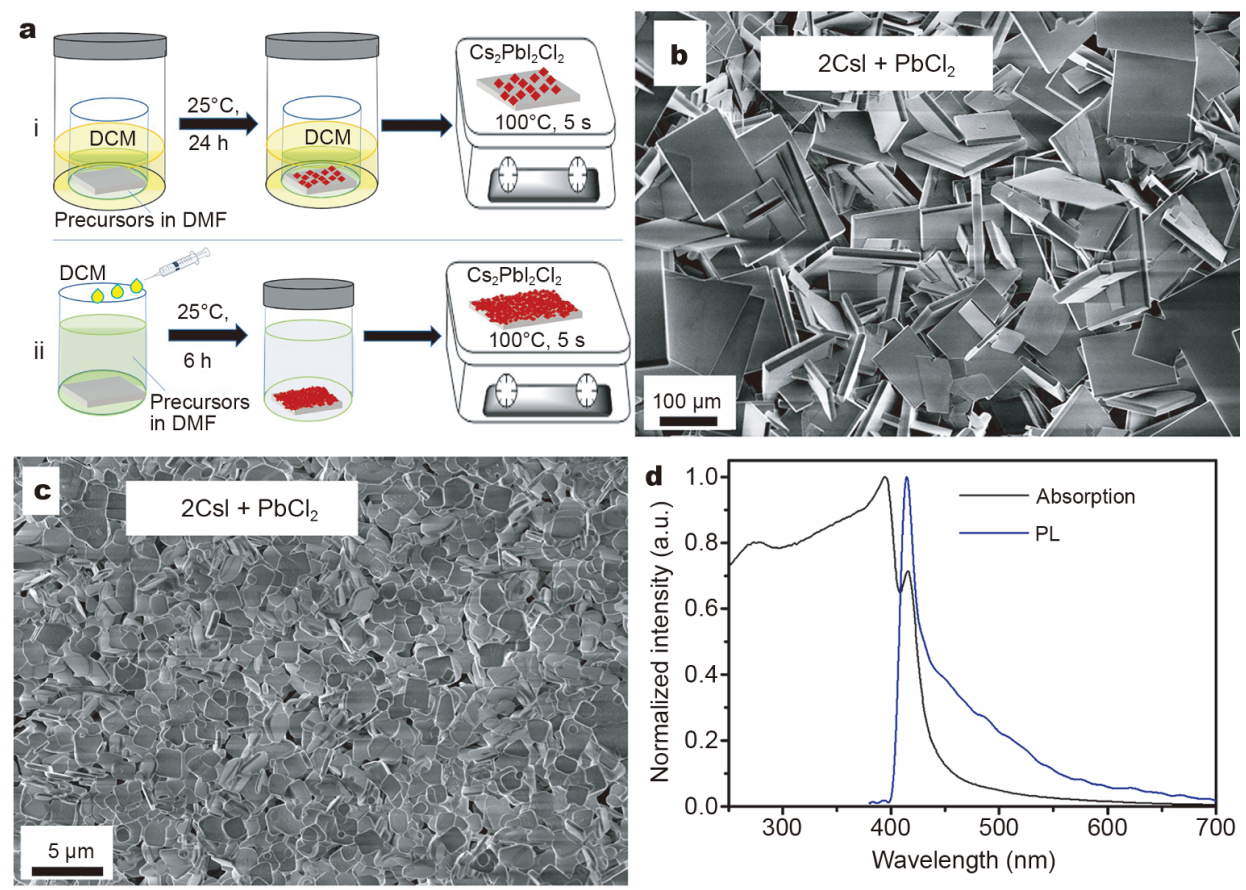

Figure 1 (a) i. Synthesis schematic diagram of large square $\mathrm{Cs}_{2} \mathrm{PbI}_{2} \mathrm{Cl}_{2}$ microplates. The precursor is $2 \mathrm{CsI}+\mathrm{PbCl}_{2}$ or $2 \mathrm{CsCl}+\mathrm{PbI}_{2}$. ii. Synthesis schematic diagram of small $\mathrm{Cs}_{2} \mathrm{PbI}_{2} \mathrm{Cl}_{2}$ microplates. The DCM was injected at conditions of $500 \mathrm{r} \mathrm{s}^{-1}, 10 \mathrm{~s}$. The products were baked on the hot plate at $100^{\circ} \mathrm{C}$ for $5 \mathrm{~s}$. (b) SEM image of large square $\mathrm{Cs}_{2} \mathrm{PbI}_{2} \mathrm{Cl}_{2}$ microplates with size of $10-20 \mu \mathrm{m}$. (c) SEM image of small microplates with size of $1-2 \mu \mathrm{m}$, which is defined as a microcrystalline thin film in this work. (d) Linear absorption and PL spectra of $\mathrm{Cs}_{2} \mathrm{PbI}_{2} \mathrm{Cl}_{2}$ microplates. The PL was monitored under low pump fluence of $325 \mathrm{~nm}$ CW laser.

thesized by the antisolvent-assisted crystallization method (Fig. 1a). Fig. 1b shows the top-view SEM image of the square $\mathrm{Cs}_{2} \mathrm{PbI}_{2} \mathrm{Cl}_{2}$ microplates with typical edge lengths of $10-20 \mu \mathrm{m}$. These large sized microplates were obtained by antisolvent vapor-assisted slow crystallization method (Fig. 1a-i). Another type of $\mathrm{Cs}_{2} \mathrm{PbI}_{2} \mathrm{Cl}_{2}$ microplates with sizes of as small as $1-2 \mu \mathrm{m}$, looks like a thin film in the macroscopic scale (Fig. 1c). These small sized microplates were obtained by the antisolvent dripping-assisted fast crystallization method (Fig. 1a-ii). Small sized microcrystal thin film is denser than large sized one because the antisolvent dripping-assisted fast crystallization can induce many nucleation centers in a very short time. In addition, $\mathrm{Cs}_{2} \mathrm{PbI}_{2} \mathrm{Cl}_{2}$ has the advantage of simplified preparation with low cost because it can be synthesized by different room-temperature solution-processed methods (Fig. S1). Fig. 1d shows the optical absorption and PL spectra of $\mathrm{Cs}_{2} \mathrm{PbI}_{2} \mathrm{Cl}_{2}$ microplates. These microplates show a strong absorbance in the ultraviolet region with an absorption edge at $410 \mathrm{~nm}$. Meanwhile, $\mathrm{Cs}_{2} \mathrm{PbI}_{2} \mathrm{Cl}_{2}$ microplates show a violet emission peak at $412 \mathrm{~nm}$ under a low-level CW laser pumping. The optical bandgap of $\mathrm{Cs}_{2} \mathrm{PbI}_{2} \mathrm{Cl}_{2}$ is estimated to be $3.01 \mathrm{eV}$ from the linear extrapolation of Kubelka-Munk function (Fig. S2).
The XRD patterns of the as-grown microplates match well with that of the reported 2D RP phase $\mathrm{Cs}_{2} \mathrm{PbI}_{2} \mathrm{Cl}_{2}$ single crystal (Fig. 2a) [15], which indicates that the obtained microplate is pure $\mathrm{Cs}_{2} \mathrm{PbI}_{2} \mathrm{Cl}_{2}$ phase. EDX spectroscopy analysis shows that the molar ratio of Cl:I:Cs: $\mathrm{Pb}$ is in accordance with the stoichiometric ratio of $\mathrm{Cs}_{2} \mathrm{PbI}_{2} \mathrm{Cl}_{2}$ (Fig. S3a), which further verifies the purity of the obtained $\mathrm{Cs}_{2} \mathrm{PbI}_{2} \mathrm{Cl}_{2}$ microplates. Fig. $2 \mathrm{~b}$ shows $\mathrm{PL}$ spectra of $\mathrm{Cs}_{2} \mathrm{PbI}_{2} \mathrm{Cl}_{2}$ microplates under $325 \mathrm{~nm} \mathrm{CW}$ laser excitation. Under low excitation intensity of $0.2 \mathrm{~mW}$, only a violet emission peak at $412 \mathrm{~nm}$ can be observed. With the increase of excitation intensity, a new emission peak centered at about $637 \mathrm{~nm}$ unexpectedly emerges. The PL intensities of both two emission peaks increase with the increase of excitation intensity (Fig. 2c). However, the red emission band increases rapidly compared with the violet emission band. Contrastively, this red band emission was hardly observed under $150 \mathrm{fs}$ pulsed $400 \mathrm{~nm}$ laser (Fig. S4). Compared with cold light source of pulse laser, CW laser is a hot light source that can induce thermal energy during the excitation/irradiation process. Thus, it can be speculated that the emergence of red emission band originates from light-induced thermal energy-driven phase transition. 

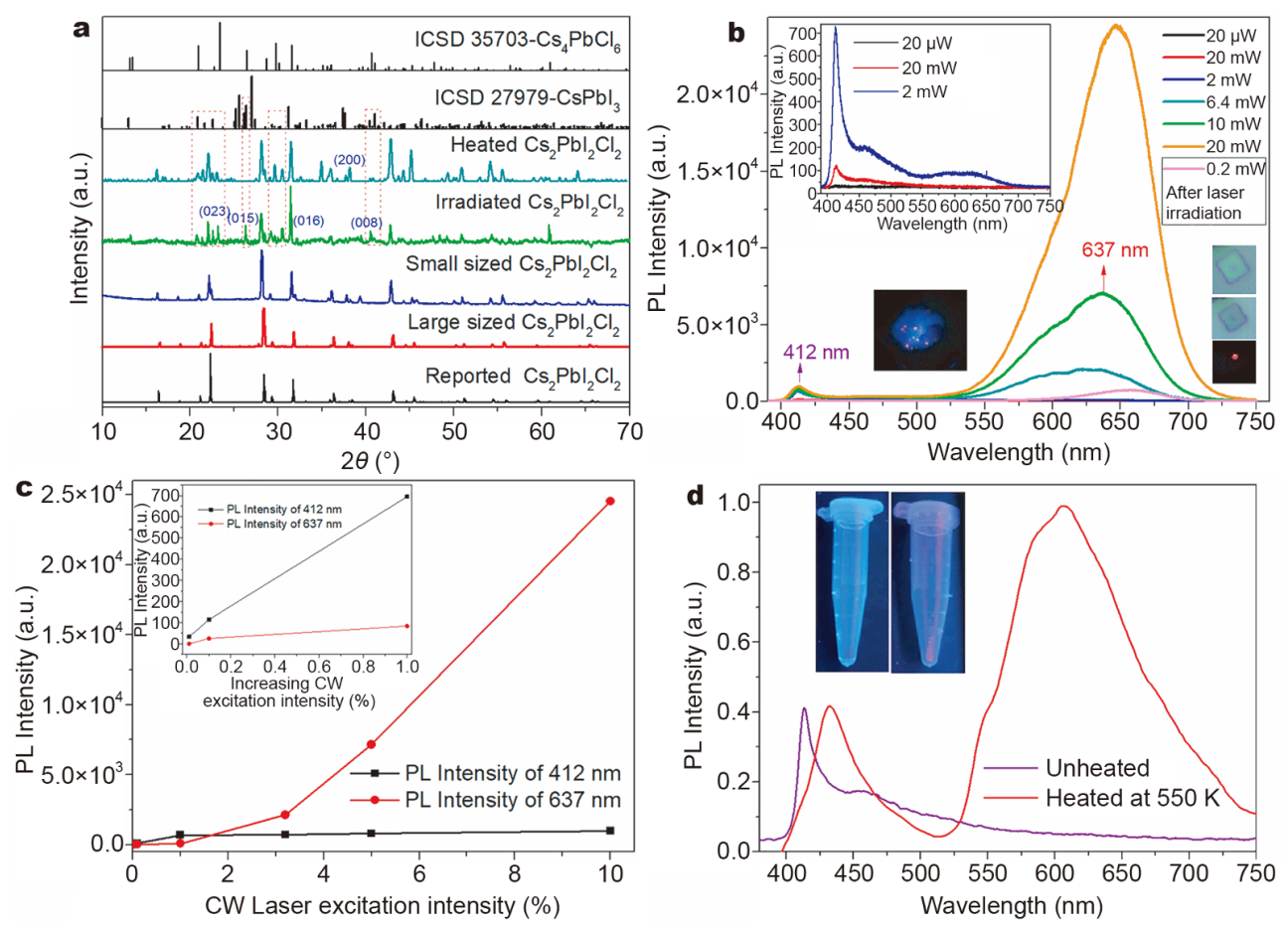

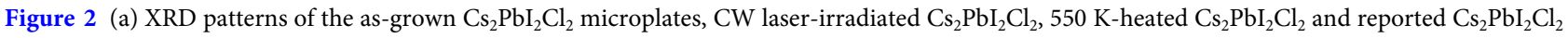
[15], compared with standard cards of $\mathrm{CsPb}_{3}$, and $\mathrm{Cs}_{4} \mathrm{PbCl}_{6}$. (b) PL spectra of a single $\mathrm{Cs}_{2} \mathrm{PbI}_{2} \mathrm{Cl}_{2}$ microplate with increasing $325 \mathrm{~nm} \mathrm{CW} \mathrm{laser}$ excitation intensity. The top-left inset shows the amplifying PL spectra under low pumping levels. The bottom-left inset shows the PL image of the multiple microplates after high power $\mathrm{CW}$ laser excitation. The right insets show the optical images of a single $\mathrm{Cs}_{2} \mathrm{PbI}_{2} \mathrm{Cl}_{2}$ microplate before and after high power CW laser excitation. (c) PL intensity of violet emission peak of $412 \mathrm{~nm}$ and red emission peak of $637 \mathrm{~nm}$ with the increase of CW laser excitation intensity. The inset shows the amplifying CW laser excitation power dependent PL intensity under low pumping levels. (d) PL spectra of the $\mathrm{Cs}_{2} \mathrm{PbI}_{2} \mathrm{Cl}_{2}$ microplates before and after thermal treatments at $550 \mathrm{~K}$ under $325 \mathrm{~nm}$ excitation. The insets show the fluorescent images of unheated $\mathrm{Cs}_{2} \mathrm{PbI}_{2} \mathrm{Cl}_{2}$ (left) and heated $\mathrm{Cs}_{2} \mathrm{PbI}_{2} \mathrm{Cl}_{2}$ (right) under $325 \mathrm{~nm}$ xenon lamp excitation source.

To further verify the influence of thermal energy, the structural and optical properties of unheated and heated $\mathrm{Cs}_{2} \mathrm{PbI}_{2} \mathrm{Cl}_{2}$ were investigated. As can be seen, it shows that heating at $550 \mathrm{~K}$ also can lead to the emergence of the red emission band (Fig. 2d). As shown in Fig. 2a, compared with original diffraction peaks, the XRD patterns of $\mathrm{CW}$ laser-irradiated and $550 \mathrm{~K}$-heated $\mathrm{Cs}_{2} \mathrm{PbI}_{2} \mathrm{Cl}_{2}$ exhibit many new similar diffraction peaks, which indicates the destruction of the crystal structure under thermal energy. Therefore, the light-induced phase transition in Fig. $2 \mathrm{~b}$ originates from the $\mathrm{CW}$ laser source induced thermal energy-driven changes of crystal structure. This is not a complete phase transition because many diffraction peaks of $\mathrm{Cs}_{2} \mathrm{PbI}_{2} \mathrm{Cl}_{2}$ can be clearly observed after light and thermal treatment. Partial new diffraction peaks match well with $\mathrm{CsPbI}_{3}$ phase suggesting that thermal energy has resulted in the formation of $\mathrm{CsPbI}_{3}$ phase. In spectroscopy characterizations, the characteristic emission peak of bulk $\mathrm{CsPbI}_{3}$ is around $700 \mathrm{~nm}$ according to previous publications [25-27]. To accurately verify the origin of unexpected red emission around $640 \mathrm{~nm}$, mixed $\mathrm{CsCl}$ and $\mathrm{PbI}_{2}$ precursor solutionbased microcrystals were prepared. Experiments demonstrate that microcrystals obtained from $\mathrm{CsCl}$ and $\mathrm{PbI}_{2}$ precursor solution are mixed phases of $\mathrm{CsPCCl}_{3}$ and $\mathrm{CsPbI}_{3}$ with two emission bands at about 502 and $700 \mathrm{~nm}$ (Fig. S5). This result suggests that $\mathrm{CsPbI}_{2} \mathrm{Cl}$ phase is absent or instable. Thus, the new emerged red emission band should be ascribed to $\mathrm{CsPbI}_{3}$ phase because only $\mathrm{CsPbI}_{3}$ can exhibit red emission band among possibly new emerged phases. The PL intensity of new emerged red emission is much stronger than that of original violet emission, which may be due to that the PL quantum yield of the emerged $\mathrm{CsPbI}_{3}$ phase is much higher than that of the original $\mathrm{Cs}_{2} \mathrm{PbI}_{2} \mathrm{Cl}_{2}$ crystals $[10,17,18,25]$. These results indicate that $\mathrm{Cs}_{2} \mathrm{PbI}_{2} \mathrm{Cl}_{2}$ has light-induced phase transition and photochromic features, as shown in the insets of Fig. 2b. After CW laser irradiation, very low power excitation intensity also can achieve its excitation and produce the red emission band (Fig. 2b), which 
suggests the light/thermo-induced phase transition is irreversible. In addition, this $\mathrm{CW}$ laser excitation power dependent photochromic feature of $\mathrm{Cs}_{2} \mathrm{PbI}_{2} \mathrm{Cl}_{2}$ enables its usage as a $\mathrm{CW}$ laser power detection material.

In order to further confirm the existence of $\mathrm{CsPbI}_{3}$ phase in these microplates after light/thermo-induced phase transition in a figurative way, TEM analysis was used. Before CW laser irradiation, the high-resolution TEM image of the obtained $\mathrm{Cs}_{2} \mathrm{PbI}_{2} \mathrm{Cl}_{2}$ shows a characteristic lattice spacing of $0.40 \mathrm{~nm}$ indexed to (110) crystal plane (Fig. 3a), which is in good agreement with previous studies $[15,17]$. After CW laser irradiation, the TEM result shows a characteristic $\mathrm{Cs}_{2} \mathrm{PbI}_{2} \mathrm{Cl}_{2}$ lattice spacing of $0.40 \mathrm{~nm}$ [17], characteristic $\mathrm{CsPbI}_{3}$ lattice spacings of 0.34 and $0.24 \mathrm{~nm}$ indexed to (015) and (200) crystal planes, respectively [28], and a much larger lattice spacing of $1.06 \mathrm{~nm}$ (Fig. 3b). The fringe with a significantly large lattice spacing of $1.06 \mathrm{~nm}$ is Moiré fringe, which indicates two overlapping lattice fringes between two crystals $[24,29]$. In general, a kind of small lattice fringes appear simultaneously with Moiré fringes, and other lattice lines with different orientations are not visible [30]. Herein, Moiré fringes in Fig. 3b result from the overlapping lattice fringes between $\mathrm{Cs}_{2} \mathrm{PbI}_{2} \mathrm{Cl}_{2}$ and $\mathrm{CsPbI}_{3}$ lattices. This is a direct evidence that demonstrates the formation of $\mathrm{CsPbI}_{3}$ phase from the inside of $\mathrm{Cs}_{2} \mathrm{PbI}_{2} \mathrm{Cl}_{2}$ crystals by heating or CW laser irradiation. According to the size limit of crystal lattices, the formed $\mathrm{CsPbI}_{3}$ phase should be nanocrystals. The XRD patterns show that the new emerged $\mathrm{CsPbI}_{3}$ phase preferentially aligned along the (023), (015), (016), (200) and (008) planes (Fig. 2a). Some main diffraction peaks typically observed in standard $\mathrm{CsPbI}_{3}$ could not be clearly resolved here. Thus, the crystal orientation of the embedded $\mathrm{CsPbI}_{3}$ phase should be limited by the original $\mathrm{Cs}_{2} \mathrm{PbI}_{2} \mathrm{Cl}_{2}$ crystal. In addition, EDX analyses show that the content of the iodine element increases after high power CW laser excitation (Figs S3b and S6). Therefore, all the evidences include XRD patterns, red characteristic emission band, TEM Moiré fringes and EDX spectra have pointed to the formation of $\mathrm{CsPbI}_{3}$ phase within $\mathrm{Cs}_{2} \mathrm{PbI}_{2} \mathrm{Cl}_{2}$ crystals during the heating or ultraviolet $\mathrm{CW}$ laser irradiation process. Meanwhile, due to the quantum size effect, the red emission band is around $640 \mathrm{~nm}$ rather than the characteristic peak of $700 \mathrm{~nm}$ of bulk $\mathrm{CsPbI}_{3}$ microcrystals. The broad full width at the half maximum of the red emission band can be ascribed to the inconsistent sizes of internal $\mathrm{CsPbI}_{3}$ nanocrystals. Herein, we define the embedded $\mathrm{CsPbI}_{3}$ nanocrystals in $\mathrm{Cs}_{2} \mathrm{PbI}_{2} \mathrm{Cl}_{2}$ crystals as the $\mathrm{CsPbI}_{3}$-in- $\mathrm{Cs}_{2} \mathrm{PbI}_{2} \mathrm{Cl}_{2}$ composite.

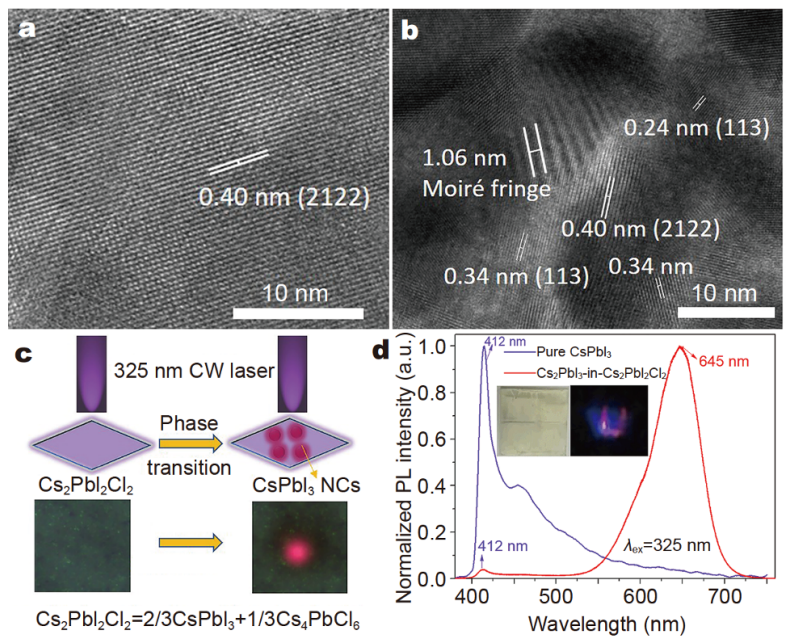

Figure 3 (a) High-resolution TEM image of the synthetic $\mathrm{Cs}_{2} \mathrm{PbI}_{2} \mathrm{Cl}_{2}$ microcrystal. (b) High-resolution TEM image of a CsPbI ${ }_{3}-$ in $_{-}-\mathrm{Cs}_{2} \mathrm{PbI}_{2} \mathrm{Cl}_{2}$ crystal shows the existent of Moiré fringe patterns with large lattice spacing of $1.06 \mathrm{~nm}$. (c) Schematic diagram of the formation of $\mathrm{CsPbI}_{3}$ nanocrystals. Bottom inserts show the fluorescent images of $\mathrm{Cs}_{2} \mathrm{PbI}_{2} \mathrm{Cl}_{2}$ microcrystalline thin film before and after $\mathrm{CW}$ laser irradiation, respectively. (d) Normalized PL spectra of pure $\mathrm{CsPbI}_{3}$ and $\mathrm{CsPbI}_{3}$-in$\mathrm{Cs}_{2} \mathrm{PbI}_{2} \mathrm{Cl}_{2}$ under $325 \mathrm{~nm}$ excitation. Left inset shows the optical image of $\mathrm{Cs}_{2} \mathrm{PbI}_{2} \mathrm{Cl}_{2}$ microcrystalline thin film; right inset shows the optical image of $\mathrm{CsPbI}_{3}$-in- $\mathrm{Cs}_{2} \mathrm{PbI}_{2} \mathrm{Cl}_{2}$ microcrystalline thin film with red emission along the " $U$ " pattern.

Fig. $3 \mathrm{c}$ shows the schematic diagram of the formation of $\mathrm{CsPbI}_{3}$ nanocrystals. The $325 \mathrm{~nm}$ CW laser irradiation will result in the formation of thermal energy that drives the chemical reaction and ionic migration at internal crystal lattice of $\mathrm{Cs}_{2} \mathrm{PbI}_{2} \mathrm{Cl}_{2}$. Based on the comparisons of XRD patterns in Fig. 2a, many XRD diffraction peaks of $\mathrm{CW}$ laser-irradiated and $550 \mathrm{~K}$-heated $\mathrm{Cs}_{2} \mathrm{PbI}_{2} \mathrm{Cl}_{2}$ match well with the standard cards of $\mathrm{CsPbI}_{3}$ and $\mathrm{Cs}_{4} \mathrm{PbCl}_{6}$. Thus, in view of the emergence of red emission band, the dominant chemical reaction is $\mathrm{Cs}_{2} \mathrm{PbI}_{2} \mathrm{Cl}_{2}=2 / 3 \mathrm{CsPbI}_{3}+$ $1 / 3 \mathrm{Cs}_{4} \mathrm{PbCl}_{6}$ (I) during the phase transition process. The previous study has calculated that decomposition pathway I is thermodynamically favorable because of the positive decomposition energy [16]. After CW laser irradiation or $550 \mathrm{~K}$ heating, a few XRD diffraction peaks match well with other phases including $\mathrm{PbCl}_{2}, \mathrm{CsI}, \mathrm{PbI}_{2}$, $\mathrm{CsCl}, \mathrm{CsPbCl}_{3}$ and $\mathrm{Cs}_{4} \mathrm{PbI}_{6}$, suggesting that some side reactions occurred during the light/thermo-induced degradation in $\mathrm{Cs}_{2} \mathrm{PbI}_{2} \mathrm{Cl}_{2}$ (Fig. S7). Hence, the red emissive $\mathrm{CsPbI}_{3}$ nanocrystal is one of the main products resulting from the light/thermo-induced phase transition. Contrastively, pulse laser excitation hardly leads to the phase transition/red emission (Fig. S4) since very less thermal energy has been produced during the excitation process. 
The optical images in Fig. $3 c$ show that very weak and almost invisible violet emission turned into bright and macroscopic red emission after $\mathrm{CW}$ laser processing in $\mathrm{Cs}_{2} \mathrm{PbI}_{2} \mathrm{Cl}_{2}$ microcrystalline thin film. Significantly, the PL intensity of the new emerged red emission band is much larger than the intrinsic violet emission of $\mathrm{Cs}_{2} \mathrm{PbI}_{2} \mathrm{Cl}_{2}$ (Figs $2 \mathrm{~b}$ and $3 \mathrm{~d}$ ). This photochromic ability of $\mathrm{Cs}_{2} \mathrm{PbI}_{2} \mathrm{Cl}_{2}$ enables it to be used as an optical image encryption material. For instance, ultraviolet $\mathrm{CW}$ laser processed patterns in $\mathrm{Cs}_{2} \mathrm{PbI}_{2} \mathrm{Cl}_{2}$ thin films can be used as anti-counterfeit labels. As shown in the right inset of Fig. 3d, red emission along the "U" pattern can be clearly observed, while other regions do not show red emission. Thus, the marked red emission based on the designed patterns in $\mathrm{CsPbI}_{3}$-in- $\mathrm{Cs}_{2} \mathrm{PbI}_{2} \mathrm{Cl}_{2}$ thin films can be used as specific signals to be quickly identified.

The time-dependent PL intensity of phase transition and stability of $\mathrm{Cs}_{2} \mathrm{PbI}_{2} \mathrm{Cl}_{2}$ is another issue for the evaluation of its practical application. Fig. 4a shows timedependent $\mathrm{PL}$ intensity of $\mathrm{Cs}_{2} \mathrm{PbI}_{2} \mathrm{Cl}_{2}$ during the phase transition process. The red emission becomes bright with the increase of irradiation time due to the increase of $\mathrm{CsPbI}_{3}$ phase (insets of Fig. 4a). The PL intensity of the red emission band increases in the first $50 \mathrm{~s}$ and after that keeps an approximate constant with the increase of irradiation time within 50-70 s. Hence, with the formation of $\mathrm{CsPbI}_{3}$ within the crystals, the mixture involving $\mathrm{CsPbI}_{3}$-in- $\mathrm{Cs}_{2} \mathrm{PbI}_{2} \mathrm{Cl}_{2}$ composite will reach a stable phase state during the irreversible phase transition [31]. Only $\mathrm{CsPbI}_{3}$ can exhibit red emission among all the mixture phases. Further, the photostability of $\mathrm{CsPbI}_{3}$-in$\mathrm{Cs}_{2} \mathrm{PbI}_{2} \mathrm{Cl}_{2}$ and pure $\mathrm{CsPbI}_{3}$ microcrystals were evaluated, as shown in Fig. 4b. Compared with the original intensity, the $\mathrm{PL}$ intensity of $\mathrm{CsPbI}_{3}$-in- $\mathrm{Cs}_{2} \mathrm{PbI}_{2} \mathrm{Cl}_{2}$ can remain about $60 \%$ while pure $\mathrm{CsPbI}_{3}$ only remain about $20 \%$ after 45 min of sustaining illumination with $325 \mathrm{~nm} \mathrm{CW}$ laser (Fig. 4c, d). This result demonstrates that $\mathrm{CsPbI}_{3}$-in$\mathrm{Cs}_{2} \mathrm{PbI}_{2} \mathrm{Cl}_{2}$ has better stability than pure $\mathrm{CsPbI}_{3}$ since in the $\mathrm{CsPbI}_{3}$-in- $\mathrm{Cs}_{2} \mathrm{PbI}_{2} \mathrm{Cl}_{2}$ composite, $\mathrm{CsPbI}_{3}$ nanocrystals are embedded in $\mathrm{Cs}_{2} \mathrm{PbI}_{2} \mathrm{Cl}_{2}$ matrix microcrystals that offer a natural barrier to prevent the degeneration of internal $\mathrm{CsPbI}_{3}$ nanocrystals.

\section{CONCLUSIONS}

In summary, the light- and thermo-induced phase transition and photochromic feature of $\mathrm{Cs}_{2} \mathrm{PbI}_{2} \mathrm{Cl}_{2}$ have been
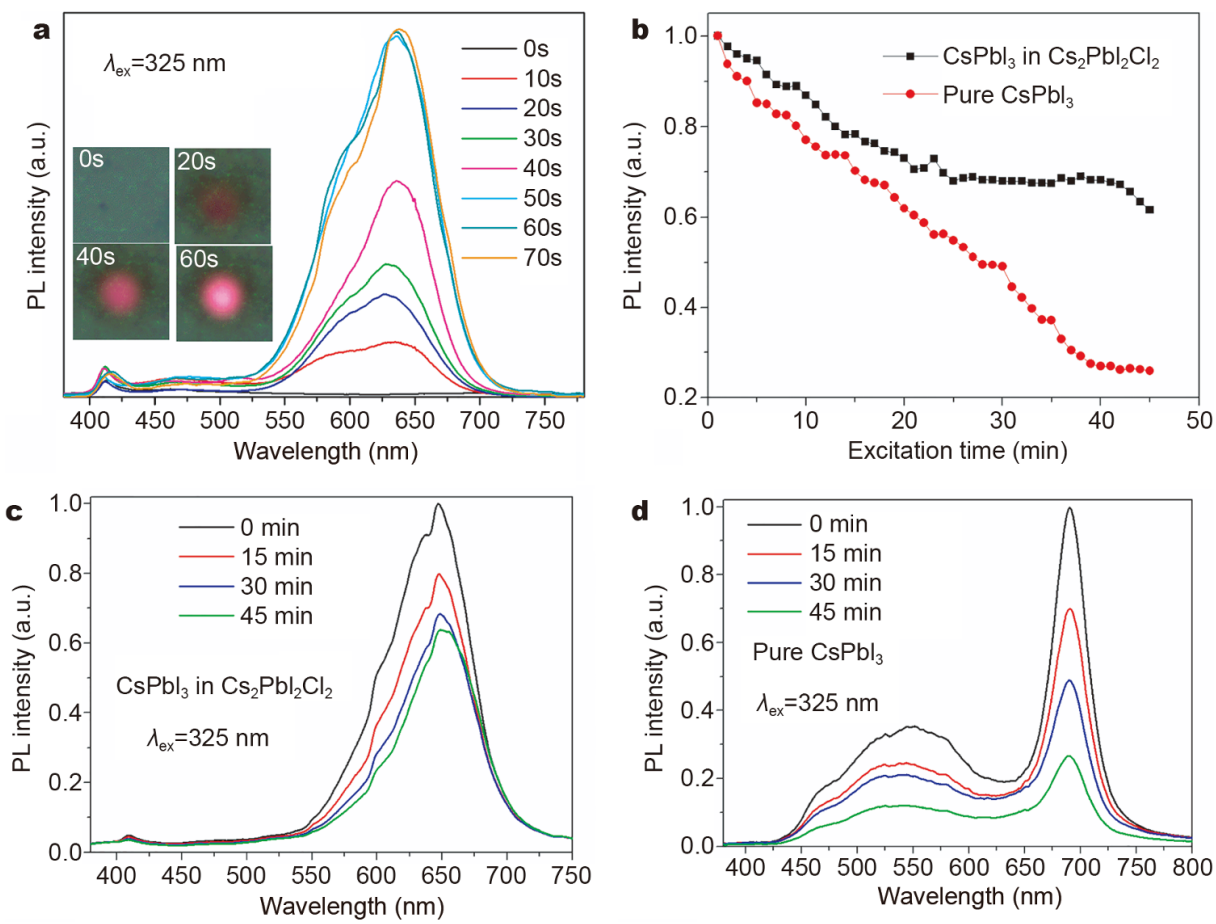

Figure 4 (a) Time-dependent PL intensity of $\mathrm{Cs}_{2} \mathrm{PbI}_{2} \mathrm{Cl}_{2}$ under $325 \mathrm{~nm} \mathrm{CW}$ laser excitation during the phase transition process. Four insets show the fluorescence images of $\mathrm{Cs}_{2} \mathrm{PbI}_{2} \mathrm{Cl}_{2}$ after different $\mathrm{CW}$ laser irradiation times of $0,20,40$, and $60 \mathrm{~s}$, respectively. (b) Integrated emission intensity changes of $\mathrm{CsPbI}_{3}$-in- $\mathrm{Cs}_{2} \mathrm{PbI}_{2} \mathrm{Cl}_{2}$ and pure $\mathrm{CsPbI}_{3}$ under constant $\mathrm{CW}$ laser excitation of $325 \mathrm{~nm}$ in ambient atmosphere. Evolution of PL spectra after different illumination times under $325 \mathrm{~nm} \mathrm{CW}$ laser excitation at about $24^{\circ} \mathrm{C}, 40 \%$ relative humidity atmosphere of $(\mathrm{c}) \mathrm{CsPbI}_{3}-\mathrm{in}_{-}-\mathrm{Cs}_{2} \mathrm{PbI}_{2} \mathrm{Cl}_{2}$ microcrystals and (d) pure $\mathrm{CsPbI}_{3}$ microcrystals. 
studied. Antisolvent vapor/dripping-assisted slow/fast crystallization methods are developed to synthesize $\mathrm{Cs}_{2} \mathrm{PbI}_{2} \mathrm{Cl}_{2}$ microplates/thin films. The intrinsic violet emission band of $\mathrm{Cs}_{2} \mathrm{PbI}_{2} \mathrm{Cl}_{2}$ is around $412 \mathrm{~nm}$ with a wide band gap. Both $\mathrm{CW}$ laser irradiation and thermal energy can lead to a new unexpected red emission band around $640 \mathrm{~nm}$. The XRD analysis, characteristic red emission band, TEM Moiré fringes and EDX spectra indicate that this red emission band originates from the formation of $\mathrm{CsPbI}_{3}$ nanocrystals within $\mathrm{Cs}_{2} \mathrm{PbI}_{2} \mathrm{Cl}_{2}$ crystals. Compared with pure $\mathrm{CsPbI}_{3}, \mathrm{CsPbI}_{3}$-in$\mathrm{Cs}_{2} \mathrm{PbI}_{2} \mathrm{Cl}_{2}$ shows better stability. The PL intensity of the red emission increases dramatically with the increase of $\mathrm{CW}$ laser excitation power at a certain range, which enables $\mathrm{Cs}_{2} \mathrm{PbI}_{2} \mathrm{Cl}_{2}$ to be used as power detection materials. The photochromic feature of $\mathrm{Cs}_{2} \mathrm{PbI}_{2} \mathrm{Cl}_{2}$ contributes to the development of anti-counterfeit labels and specific identification applications based on the designed patterns. These results suggest $\mathrm{Cs}_{2} \mathrm{PbI}_{2} \mathrm{Cl}_{2}$ can serve as promising power detection and optical image encryption materials with excellent photochromic ability toward practical functional devices.

\section{Received 28 January 2020; accepted 7 March 2020;}

published online 27 April 2020

1 Xing G, Mathews N, Sun S, et al. Long-range balanced electronand hole-transport lengths in organic-inorganic $\mathrm{CH}_{3} \mathrm{NH}_{3} \mathrm{PbI}_{3}$. Science, 2013, 342: 344-347

2 Lin K, Xing J, Quan LN, et al. Perovskite light-emitting diodes with external quantum efficiency exceeding 20 percent. Nature, 2018, 562: $245-248$

3 Xing G, Mathews N, Lim SS, et al. Low-temperature solutionprocessed wavelength-tunable perovskites for lasing. Nat Mater, 2014, 13: 476-480

4 Wei Q, Li X, Liang C, et al. Recent progress in metal halide perovskite micro- and nanolasers. Adv Opt Mater, 2019, 7: 1900080

5 Shen $\mathrm{X}$, Chen $\mathrm{M}$, Shi $\mathrm{L}$, et al. Lasing behaviors in solution processed all-inorganic $\mathrm{CsPbBr}_{3}$ perovskite microsized crystals. Optics Commun, 2019, 453: 124354

6 Zhang N, Fan Y, Wang K, et al. All-optical control of lead halide perovskite microlasers. Nat Commun, 2019, 10: 1770

7 Feng J, Gong C, Gao H, et al. Single-crystalline layered metalhalide perovskite nanowires for ultrasensitive photodetectors. Nat Electron, 2018, 1: 404-410

8 Ma S, Cai M, Cheng T, et al. Two-dimensional organic-inorganic hybrid perovskite: from material properties to device applications. Sci China Mater, 2018, 61: 1257-1277

9 Song W, Cao G. Surface-defect passivation through complexation with organic molecules leads to enhanced power conversion efficiency and long term stability of perovskite photovoltaics. Sci China Mater, 2020, 63: 479-480

10 Song J, Li J, Li X, et al. Quantum dot light-emitting diodes based on inorganic perovskite cesium lead halides $\left(\mathrm{CsPbX}_{3}\right)$. Adv Mater, 2015, 27: 7162-7167
11 Swarnkar A, Marshall AR, Sanehira EM, et al. Quantum dot-induced phase stabilization of $\alpha-\mathrm{CsPbI}_{3}$ perovskite for high-efficiency photovoltaics. Science, 2016, 354: 92-95

12 Mei S, Liu X, Zhang W, et al. High-bandwidth white-light system combining a micro-LED with perovskite quantum dots for visible light communication. ACS Appl Mater Interfaces, 2018, 10: 56415648

13 Liao JF, Li WG, Rao HS, et al. Inorganic cesium lead halide $\mathrm{CsPbX}_{3}$ nanowires for long-term stable solar cells. Sci China Mater, 2017, 60: 285-294

14 Zeng J, Zhou H, Liu R, et al. Combination of solution-phase process and halide exchange for all-inorganic, highly stable $\mathrm{CsPbBr}_{3}$ perovskite nanowire photodetector. Sci China Mater, 2019, 62: 65-73

15 Li J, Yu Q, He Y, et al. $\mathrm{Cs}_{2} \mathrm{PbI}_{2} \mathrm{Cl}_{2}$, all-inorganic two-dimensional ruddlesden-popper mixed halide perovskite with optoelectronic response. J Am Chem Soc, 2018, 140: 11085-11090

$16 \mathrm{Xu} \mathrm{Z}$, Chen $\mathrm{M}$, Liu SF. Layer-dependent ultrahigh-mobility transport properties in all-inorganic two-dimensional $\mathrm{Cs}_{2} \mathrm{PbI}_{2} \mathrm{Cl}_{2}$ and $\mathrm{Cs}_{2} \mathrm{SnI}_{2} \mathrm{Cl}_{2}$ perovskites. J Phys Chem C, 2019, 123: 2797827985

17 Akkerman QA, Bladt E, Petralanda U, et al. Fully inorganic ruddlesden-popper double $\mathrm{Cl}-\mathrm{I}$ and triple $\mathrm{Cl}-\mathrm{Br}-\mathrm{I}$ lead halide perovskite nanocrystals. Chem Mater, 2019, 31: 2182-2190

18 Dutta A, Behera RK, Deb S, et al. Doping Mn(II) in all-inorganic ruddlesden-popper phase of tetragonal $\mathrm{Cs}_{2} \mathrm{PbCl}_{2} \mathrm{I}_{2}$ perovskite nanoplatelets. J Phys Chem Lett, 2019, 10: 1954-1959

19 Acharyya P, Maji K, Kundu K, et al. 2D nanoplates and scaled-up bulk polycrystals of ruddlesden-popper $\mathrm{Cs}_{2} \mathrm{PbI}_{2} \mathrm{Cl}_{2}$ for optoelectronic applications. ACS Appl Nano Mater, 2020, 3: 877-886

20 Ohkoshi S, Tokoro H, Hashimoto K. Temperature- and photoinduced phase transition in rubidium manganese hexacyanoferrate. Coord Chem Rev, 2005, 249: 1830-1840

21 Wales DJ, Cao Q, Kastner K, et al. 3D-printable photochromic molecular materials for reversible information storage. Adv Mater, 2018, 30: 1800159

22 Bisoyi HK, Li Q. Light-driven liquid crystalline materials: from photo-induced phase transitions and property modulations to applications. Chem Rev, 2016, 116: 15089-15166

23 Tian H, Yang S. Recent progresses on diarylethene based photochromic switches. Chem Soc Rev, 2004, 33: 85-97

24 Li X, Zhang X, Li H, et al. Solution-processed perovskite microdisk for coherent light emission. Adv Opt Mater, 2019, 7: 1900678

25 Zhang Q, Su R, Liu X, et al. High-quality whispering-gallery-mode lasing from cesium lead halide perovskite nanoplatelets. Adv Funct Mater, 2016, 26: 6238-6245

26 Wang Y, Dar MI, Ono LK, et al. Thermodynamically stabilized $\beta$ $\mathrm{CsPbI}_{3}$-based perovskite solar cells with efficiencies $>18 \%$. Science, 2019, 365: 591-595

27 Wang Q, Zheng X, Deng Y, et al. Stabilizing the $\alpha$-phase of $\mathrm{CsPbI}_{3}$ perovskite by sulfobetaine zwitterions in one-step spin-coating films. Joule, 2017, 1: 371-382

28 Sun JK, Huang S, Liu XZ, et al. Polar solvent induced lattice distortion of cubic $\mathrm{CsPbI}_{3}$ nanocubes and hierarchical self-assembly into orthorhombic single-crystalline nanowires. J Am Chem Soc, 2018, 140: 11705-11715

29 Quan LN, Quintero-Bermudez R, Voznyy O, et al. Highly emissive green perovskite nanocrystals in a solid state crystalline matrix. Adv Mater, 2017, 29: 1605945

30 Zhang $\mathrm{H}$, Wen $\mathrm{H}$, Liu Z, et al. TEM nano-Moiré evaluation for an 
invisible lattice structure near the grain interface. Nanoscale, 2017, 9: 15923-15933

31 Schlögl F. Chemical reaction models for non-equilibrium phase transitions. Z Physik, 1972, 253: 147-161

Acknowledgements This work was supported by the Macau Science and Technology Development Fund (FDCT-116/2016/A3, FDCT-091/ 2017/A2, FDCT-014/2017/AMJ and FDCT-199/2017/A3), Start-up Research Grant Fund from University of Macau (SRG2016-00002-FST), Research and Development Grant for Chair Professor Fund from University of Macau (CPG2018-00026-FST), Research Grant (SRG201600087-FST, MYRG2018-00148-IAPME and MYRG2018-00142-IAPME) from University of Macau, the National Natural Science Foundation of China (91733302, 61935017 and 61605073), and the Natural Science Foundation of Guangdong Province of China (2019A1515012186).

Author contributions Xing G and Tang $\mathrm{Z}$ conceived the idea and obtained the research grants. Li $\mathrm{X}$ designed the experiments, synthesized the materials, conducted the characterizations and wrote the manuscript. Chen $M$ and Wang B revised the manuscript. Mei S conceived the discussion and conducted the measurements of light-induced phase transition. Wang $\mathrm{K}$ contributed to the general discussion and measurements.

Conflict of interest The authors declare that they have no conflict of interest.

Supplementary information Supporting data are available in the online version of the paper.

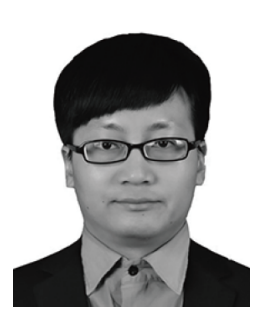

Xiaojun Li graduated from China Jiliang University with a master degree in 2016 , focusing on the preparation and luminescence properties of rare-earth doped silicon-based oxynitride phosphors. He is currently a $\mathrm{PhD}$ candidate in the Institute of Applied Physics and Materials Engineering at University of Macau, China. His current research interests are the synthesis of perovskites and related micro-nano single crystals and their photoelectric applications.

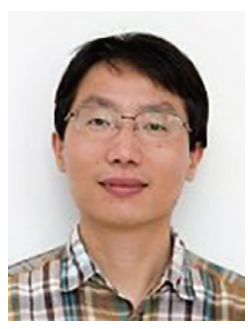

Guichuan Xing is an Assistant Professor in the Institute of Applied Physics and Materials Engineering at University of Macau, China. He received his $\mathrm{PhD}$ in physics from National University of Singapore, Singapore, in 2011 and then worked as a research assistant, research fellow, and senior research fellow in the Division of Physics \& Applied Physics at Nanyang Technological University, Singapore from 2009 to 2016. His research interests lie in the ultrafast laser spectroscopy, nano-optoelectronics, perovskites for light harvesting and light emission, nonlinear optical properties, and ultrafast carrier dynamics in novel optoelectronic materials and devices.

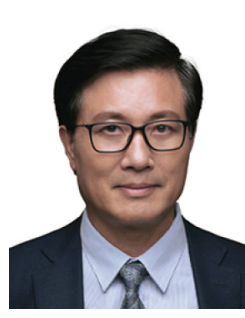

Zikang Tang is the Chair Professor and director of the Institute of Applied Physics and Materials Engineering at University of Macau, China. He obtained his $\mathrm{PhD}$ in condensed matter physics from Tohoku University, Japan in 1992. Following that he worked at Japanese Science \& Technology Agency as a research fellow (19921994). He then joined the faculty at Hong Kong University of Science \& Technology (1994-2015) and joined the University of Macau in 2016. His research focuses on nanostructured electronic materials, 2D materials, $\mathrm{ZnO}$ crystal thin films, wide-gap semiconductors, and their photoelectronic devices.

\section{全无机二维钻钛矿 $\mathrm{Cs}_{2} \mathrm{PbI}_{2} \mathrm{Cl}_{2}$ 中的光致相变和光 致变色}

李晓军 ${ }^{1}$, 陈明明 ${ }^{2}$, 梅时良 ${ }^{1}$, 王冰哲 ${ }^{1}$, 王开阳 ${ }^{1}$, 邢贵川 ${ }^{1 *}$, 汤子康 ${ }^{1 *}$

摘要 有机-无机杂化二维ruddlesden-popper (RP)钲钛矿因为其优 异的光电性能和良好的稳定性, 在太阳能电池和发光器件领域应 用前景巨大, 而受到广泛关注. 最近, 人们提出一类新型的二维 RP 相全无机钙钛矿 $\mathrm{Cs}_{2} \mathrm{PbI}_{2} \mathrm{Cl}_{2}$ 材料, 这类材料具有优异的激子吸收性 能以及良好的环境和热稳定性. 本文报道了 $\mathrm{Cs}_{2} \mathrm{PbI}_{2} \mathrm{Cl}_{2}$ 中有趣的光 致相变和光致变色现象. 在低功率连续激光激发下, $\mathrm{Cs}_{2} \mathrm{PbI}_{2} \mathrm{Cl}_{2}$ 的 室温光致发光以 $412 \mathrm{~nm}$ 处的微弱的紫色发射为主. 有趣的是, 随着 激发功率的增加, 发射颜色逐渐由紫色变为明亮的红色. 这种光致 变色起源于 $\mathrm{Cs}_{2} \mathrm{PbI}_{2} \mathrm{Cl}_{2}$ 晶体内由热能驱动的光致相变而形成的 $\mathrm{CsPb}_{3}$ 纳米晶. 由于 $\mathrm{Cs}_{2} \mathrm{PbI}_{2} \mathrm{Cl}_{2}$ 基体微晶的保护作用, 内嵌的 $\mathrm{CsPbI}_{3}$ 纳米晶的稳定性相比于纯的 $\mathrm{CsPI}_{3}$ 有明显提高. 而具有光致变色特 征的 $\mathrm{Cs}_{2} \mathrm{PbI}_{2} \mathrm{Cl}_{2}$ 可能会在光学加密中得到应用, 这在本项工作中得 到了初步证实. 